\title{
Noninvasive Ventilation in Patients With COVID-19-Related Acute Hypoxemic Respiratory Failure: A Retrospective Cohort Study
}

\section{OPEN ACCESS \\ Edited by: \\ Reza Lashgari, \\ Institute for Research in Fundamental \\ Sciences, Iran \\ Reviewed by: \\ Eduardo Luis De Vito, \\ University of Buenos Aires, Argentina \\ Shima Moein, \\ Institute for Research in Fundamental \\ Sciences (IPM), Iran \\ ${ }^{*}$ Correspondence: \\ Lei Liu \\ liulei3322@aliyun.com \\ Rongchang Chen \\ chenrc@vip.163.com \\ Chen Qiu}

qiuchen@email.jnu.edu.cn

tThese authors have contributed equally to this work and share first authorship

Specialty section:

This article was submitted to

Pulmonary Medicine,

a section of the journal

Frontiers in Medicine

Received: 05 December 2020 Accepted: 28 April 2021 Published: 24 May 2021

Citation:

Fu Y, Guan L, Wu W, Yuan J, Zha S, Wen J, Lin Z, Qiu C, Chen R and Liu L (2021) Noninvasive Ventilation in Patients With COVID-19-Related Acute Hypoxemic Respiratory Failure: A Retrospective Cohort Study. Front. Med. 8:638201.

doi: 10.3389/fmed.2021.638201

\section{Yingyun $\mathrm{Fu}^{1 \dagger}$, Lili Guan ${ }^{1 \dagger}$, Weibo $\mathrm{Wu}^{2 \dagger}$, Jing Yuan ${ }^{2 \dagger}$, Shanshan Zha ${ }^{1 \dagger}$, Junmin Wen ${ }^{3}$,} Zhenghao Lin $^{2}$, Chen Qiu ${ }^{1 *}$, Rongchang Chen ${ }^{1 *}$ and Lei Liu ${ }^{2 *}$

${ }^{1}$ Shenzhen Institute of Respiratory Diseases, Shenzhen People's Hospital (The Second Clinical Medical College, Jinan University; The First Affiliated Hospital, South University of Science and Technology), Shenzhen, China, ${ }^{2}$ National Clinical Research Center for Infectious Disease, The Third People's Hospital of Shenzhen, The Second Affiliated Hospital of Southern University of Science and Technology, Shenzhen, China, ${ }^{3}$ Fuwai Hospital Chinese Academy of Medical Sciences, Shenzhen, China

Introduction: Noninvasive ventilation (NIV) has been used to alleviate hypoxemia and dyspnea, but there is no consensus on the application of NIV in patients with coronavirus disease 2019 (COVID-19). Some staff use NIV as the rescue therapy which might lead to the adverse outcomes. This study was to identify early factors associated with intubation to help the medical staff select appropriate patients for receiving NIV treatment.

Methods: Patients with laboratory-confirmed COVID-19 who were treated with NIV in emergency department or ICU of the Third People's Hospital (the only designated hospital for treating COVID-19 in Shenzhen) between January 1 and August 31, 2020, were retrospectively analyzed.

Results: Thirty-nine patients with COVID-19 treated with NIV were included; of them, $16(41 \%)$ received endotracheal intubation and $3(8 \%)$ died. Significant differences were observed between intubated and non-intubated patients in $\mathrm{PaO}_{2} / \mathrm{FiO}_{2}$ before NIV initiation, hospitalization duration, NIV as the rescue therapy, and $\mathrm{PaO}_{2} / \mathrm{FiO}_{2}$ of $\leq 200$ $\mathrm{mmHg}$ after $1-2 \mathrm{~h}$ of NIV initiation. Notably, $1-2 \mathrm{~h}$ after $\mathrm{NIV}$ initiation, $\mathrm{a} \mathrm{PaO}_{2} / \mathrm{FiO}_{2}$ of $\leq 200$ $\mathrm{mmHg}$ (odds ratio [OR], 9.35; 95\% confidence interval [Cl], 1.84-47.62; $P=0.007$ ) and NIV as the rescue therapy (OR, 5.43; 95\% Cl, 1.09-27.12; $P=0.039)$ were the risk factors for intubation.

Conclusions: In patients with COVID-19-related acute hypoxemic respiratory failure receiving NIV, close attention should be paid to $\mathrm{PaO}_{2} / \mathrm{FiO}_{2}$ after $1-2 \mathrm{~h}$ of NIV initiation. Also, using NIV as rescue therapy should draw our awareness that it might delay escalation of respiratory support and lead to adverse outcomes.

Keywords: coronavirus disease 2019, noninvasive ventilation, rescue therapy, delayed intubation, acute hypoxemic respiratory failure 


\section{INTRODUCTION}

Since the identification of an initial cluster of patients in December 2019, the coronavirus disease 2019 (COVID-19) pandemic has continued to wreak global havoc. So far, $\sim 20 \%$ of patients have been categorized as severely or critically ill, presenting with acute hypoxemic respiratory failure (AHRF) (1). Medical resources have been in short supply owing to the vast number of patients. Moreover, early intubation has inevitably led to some complications in these patients (2).

Using noninvasive respiratory support to treat patients without intubation can save medical resources and reduce the incidence of pain and complications (3-5). Noninvasive ventilation (NIV) has been used to alleviate hypoxemia and dyspnea in patients with COVID-19 during the pandemic (6). However, using NIV to treat AHRF remains showing some discrepancies, probably due to the patient selection and NIV parameter settings $(7,8)$. For now, there is no unified consensus on the application of NIV in patients with COVID-19-related AHRF; most of the consensus are based on previous experience in the treatment of viral pneumonia $(9,10)$. Medical staff tend to base their choice on personal preference or experience because there is no evidence-based recommendation for the NIV selection $(6,11)$. In addition, some staff tend to use NIV as the rescue therapy after conventional oxygen therapy or highflow nasal oxygen therapy (HFNO) had failed, which might delay the escalation of respiratory support and lead to the adverse outcomes.

Therefore, in this retrospective cohort study, we aimed to identify early factors associated with intubation to help the medical staff select appropriate patients for receiving NIV treatment and avoid delayed intubation.

\section{METHODS}

In this retrospective cohort study, patients with laboratoryconfirmed COVID-19 in the emergency department or ICU of the Third People's Hospital which is the only designated hospital for treating COVID-19 in Shenzhen, a megacity with a population of more than 10 million, between January 1 and August 31, 2020, were included (Figure 1). All patients who were treated with NIV during their hospital stay and were identified from electronic medical records, were included. The treatment regimen was in accordance with the Chinese COVID2019 treatment guidelines (12), and all patients have already been discharged from the hospital, except three deaths.

Demographic and clinical data and information on ventilatory settings and arterial blood gas samples were collected before and $1-2 \mathrm{~h}$ after NIV initiation. Two clinicians independently gathered demographic and clinical data from electronic medical records using standardized data collection forms; any variances or discrepancies were discussed, and a third clinician moderated and adjudicated the validity of disputed data.

NIV as the initial treatment was defined as using NIV as the first choice to correct hypoxemia after using conventional oxygen therapy. NIV as the rescue therapy was defined as using NIV to treat patients with AHRF in whom treatment with HFNO had failed. The criteria for intubation included the signs of persisting or worsening respiratory failure, hemodynamic instability, or consciousness deterioration (12). The primary outcome of the study was to identify early factors associated with intubation, whereas secondary outcomes included hospitalization duration and all-cause mortality during hospitalization.

SPSS version 19.0 (IBM SPSS Statistics, Armonk, NY, USA) was used for data analysis. Data were presented as median (interquartile range $[\mathrm{IQR}]$ ), or number (percentage)

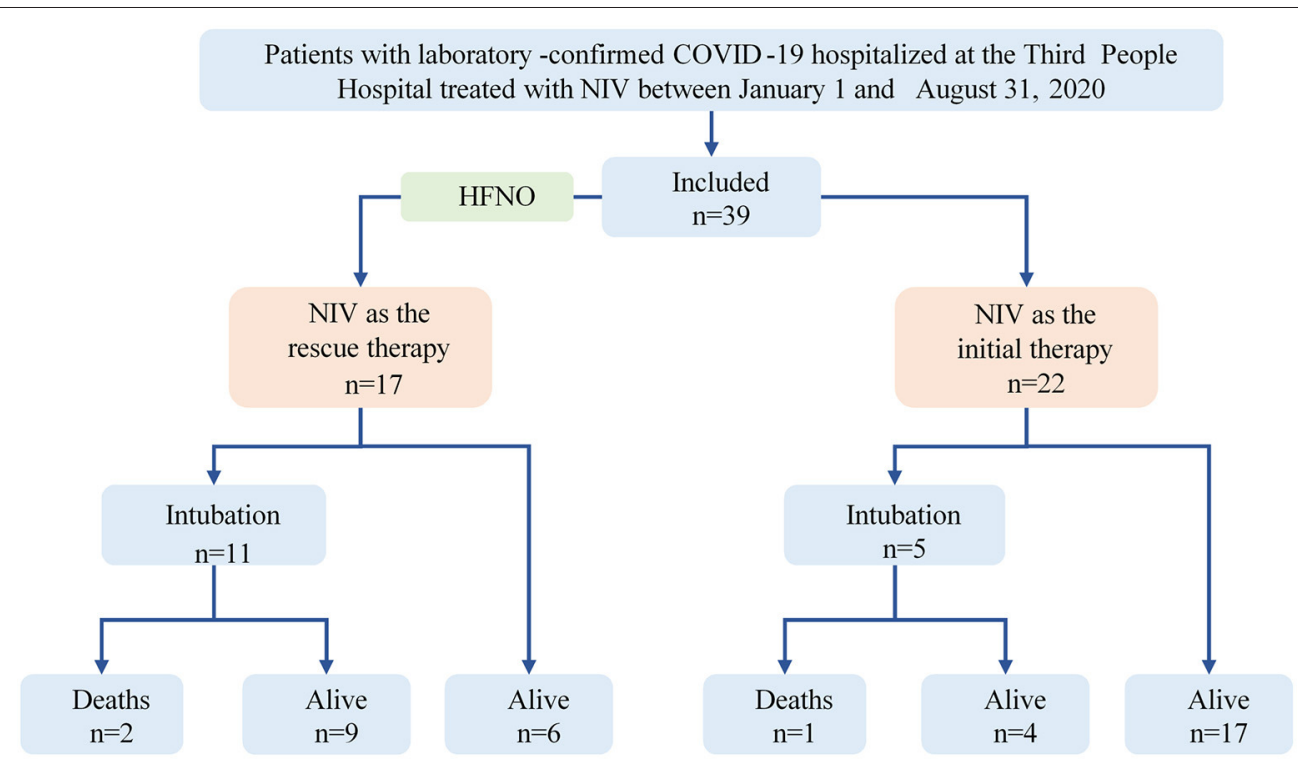

FIGURE 1 | Flowchart of the study. COVID-19, coronavirus disease 2019; NIV, noninvasive ventilation; HFNO, high-flow nasal oxygen therapy. 
as appropriate. For continuous variables, comparisons were performed using Student's $t$-test for normally distributed data and nonparametric test for non-normally distributed data. For categorical variables, Pearson's chi-square test or Fisher's exact test was used. Factors associated with intubation were assessed via backward multivariate logistic regression analyses. The KaplanMeier method was used to evaluate the 28th day intubation rate from hospital admission and symptom onset, and between-group differences were estimated using the log-rank test. A two-tailed $P$
$<0.05$ was considered significant. The ethics committee of the Third People's Hospital approved this study, and the trial was registered with www.chictr.org.cn (ChiCTR2000039567).

\section{RESULTS}

In total, among 423 hospitalized patients with COVID-19 in Shenzhen, 39 patients with COVID-19 (9\%) who were treated

TABLE 1 | Comparison of baseline clinical characteristics, NIV therapy, and clinical outcomes in patients who required intubation or not intubation.

\begin{tabular}{|c|c|c|c|c|c|}
\hline & Intubation $(n=16)$ & Nonintubation $(n=23)$ & Unadjusted $p$-value & OR $(95 \% \mathrm{Cl})$ & Adjusted $p$-value \\
\hline \multicolumn{6}{|l|}{ Baseline clinical characteristics } \\
\hline Age, years & $65.0(58.5-69.0)$ & $62.0(59.5-65.0)$ & 0.343 & & \\
\hline Male, $n(\%)$ & $11(68.8)$ & $15(65.2)$ & 0.818 & & \\
\hline BMI, kg/m² & $24.6(21.7-26.2)$ & $25.4(22.8-27.1)$ & 0.394 & & \\
\hline White blood cell count, $\times 10^{9} / \mathrm{L}$ & $5.5(4.1-6.9)$ & $4.3(3.5-5.1)$ & 0.112 & & \\
\hline Lymphocyte count, $\times 10^{9} / \mathrm{L}$ & $1.0(0.9-1.3)$ & $1.1(0.8-1.4)$ & 0.746 & & \\
\hline Procalcitonin, ng/ml & $0.08(0.06-0.11)$ & $0.07(0.05-0.10)$ & 0.563 & & \\
\hline D-dimer, $\mu \mathrm{g} / \mathrm{ml}$ & $0.7(0.5-1.2)$ & $0.6(0.4-0.8)$ & 0.107 & & \\
\hline \multicolumn{6}{|l|}{ Comorbidities } \\
\hline Chronic respiratory disease, $n(\%)$ & $2(12.5)$ & $1(4.3)$ & 0.557 & & \\
\hline Hypertension, $n$ (\%) & $7(43.8)$ & $7(30.4)$ & 0.503 & & \\
\hline Chronic cardiovascular disease, $n(\%)$ & $3(3.3)$ & $5(4.7)$ & 0.820 & & \\
\hline Chronic kidney disease, $n$ (\%) & $0(0)$ & $1(4.3)$ & 0.398 & & \\
\hline Chronic hepatic disease, $n$ (\%) & $1(6.3)$ & $1(4.3)$ & 0.791 & & \\
\hline Diabetes, $n(\%)$ & $3(18.8)$ & $4(17.4)$ & 0.913 & & \\
\hline Cancer, $n(\%)$ & $1(6.3)$ & $1(4.3)$ & 0.791 & & \\
\hline \multicolumn{6}{|l|}{ Clinical data before NIV therapy } \\
\hline Respiratory rate, breaths/min & $25.0(24.8-26.5)$ & $23.0(22.0-28.5)$ & 0.159 & & \\
\hline Heart rate, breaths/min & $83.0(77.0-88.0)$ & $81.0(74.0-89.0)$ & 0.938 & & \\
\hline $\mathrm{pH}$ & $7.46(7.45-7.48)$ & $7.45(7.43-7.47)$ & 0.534 & & \\
\hline $\mathrm{PaO}_{2}, \mathrm{mmHg}$ & $72.1(64.6-78.8)$ & $72.2(63.5-80.5)$ & 0.855 & & \\
\hline $\mathrm{PaO}_{2} / \mathrm{FiO}_{2}, \mathrm{mmHg}$ & $144.1(126.0-169.5)$ & $180.0(151.4-226.5)$ & 0.016 & & \\
\hline $\begin{array}{l}\text { The time interval from symptom onset } \\
\text { to initiating NIV, days }\end{array}$ & $10.5(5.8-13.5)$ & $11.0(9.0-13.5)$ & 0.489 & & \\
\hline NIV as the rescue therapy, $n(\%)$ & $11(68.8)$ & $6(26.1)$ & 0.011 & $5.43(1.09-27.12)$ & 0.039 \\
\hline APACHE II & $12.0(10.8-13.5)$ & $10.0(8.5-12.0)$ & 0.094 & & \\
\hline \multicolumn{6}{|l|}{ Clinical data after $1-2 \mathrm{~h}$ NIV therapy } \\
\hline Respiratory rate, breaths/min & $24.0(21.5-28.5)$ & $22.0(20.0-23.5)$ & 0.143 & & \\
\hline Heart rate, breaths/min & $78.0(73.5-85.5)$ & $78.0(71.0-86.0)$ & 0.935 & & \\
\hline Pressure support, $\mathrm{cmH}_{2} \mathrm{O}$ & $6.0(6.0-6.3)$ & $7.0(6.0-7.0)$ & 0.046 & & \\
\hline EPAP, $\mathrm{cmH}_{2} \mathrm{O}$ & $6.0(6.0-6.3)$ & $6.0(6.0-7.0)$ & 0.703 & & \\
\hline $\mathrm{PaO}_{2}, \mathrm{mmHg}$ & 87.2 (77.6-92.8) & 110.0 (99.5-125.6) & $<0.001$ & & \\
\hline $\mathrm{PaO}_{2} / \mathrm{FiO}_{2}, \mathrm{mmHg}$ & $181.3(155.2-204.7)$ & $265.0(215.2-306.7)$ & $<0.001$ & & \\
\hline $\begin{array}{l}\mathrm{PaO}_{2} / \mathrm{FiO}_{2} \text { of } \leq 200 \mathrm{mmHg} \text { after } \\
1-2 \mathrm{~h} \text { of NIV initiation, } n(\%)\end{array}$ & $11(68.8)$ & $4(17.4)$ & 0.002 & $9.35(1.84-47.62)$ & 0.007 \\
\hline \multicolumn{6}{|l|}{ Clinical outcomes } \\
\hline Hospitalization duration, days & $46.0(35.0-52.5)$ & $34.0(28.0-40.0)$ & 0.007 & & \\
\hline In-hospital mortality, n (\%) & $3(18.8)$ & $0(0)$ & 0.061 & & \\
\hline
\end{tabular}

Data represent as median (interquartile range) or $n$ (\%).

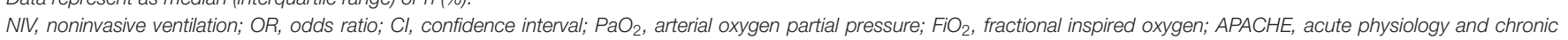
health evaluation; EPAP, expiratory positive airway pressure.

Variables entered in the model of logistic regression were: using NIV as the rescue therapy, APACHE II, pressure support, $\mathrm{PaO}_{2} / \mathrm{FiO}_{2}$ of $\leq 200 \mathrm{mmHg}$ after $1-2 \mathrm{~h}$ of $\mathrm{NIV}$ initiation. 
with NIV were included in the study; of them, 16 (41\%) received endotracheal intubation, and $3(8 \%)$ died. All patients received bilevel ventilation. The median initial inspiratory positive airway pressure and expiratory positive airway pressure were 13.0 (IQR, 12.0-14.0) $\mathrm{cmH}_{2} \mathrm{O}$ and 6.0 (IQR, 6.0-6.5) $\mathrm{cmH}_{2} \mathrm{O}$, respectively, with a median fractional inspired oxygen $\left(\mathrm{FiO}_{2}\right)$ of 0.5 (IQR, 0.4-0.5).

There is no significant difference between intubated and nonintubated patients in the baseline demographic, comorbidities, severity blood markers (white blood cell count, lymphocyte count, procalcitonin, d-dimer) and severity scores (APACHE II score) (Table 1). Patients who required intubation had lower arterial oxygen partial pressure $\left(\mathrm{PaO}_{2}\right)$ to $\mathrm{FiO}$ ratio $\left(\mathrm{PaO}_{2} / \mathrm{FiO}_{2}\right)$ before receiving NIV, higher proportion of using NIV as the rescue therapy, and longer hospitalization duration (Table 1). Significant differences were observed between intubated and non-intubated patients in $\mathrm{PaO}_{2} / \mathrm{FiO}_{2}$ before NIV initiation (144.1 [IQR, 126.0-169.5] mmHg vs. 180.0 [IQR, 151.4-226.5] mmHg; $P=0.016$ ), hospitalization duration (46.0 [IQR, 35.052.5] days vs. 34.0 [IQR, 28.0-40.0] days; $P=0.007)$, NIV as the rescue therapy (68.8 vs. $26.1 \% ; P=0.011$ ), $\mathrm{PaO}_{2} / \mathrm{FiO}_{2}$ of $\leq 200 \mathrm{mmHg}$ after $1-2 \mathrm{~h}$ of NIV initiation (68.8 vs. $17.4 \%$; $P=$ 0.002 ), and the pressure support level (6.0 [IQR, 6.0-6.3] $\mathrm{cmH}_{2} \mathrm{O}$ vs. 7.0 [IQR, 6.0-7.0] $\left.\mathrm{cmH}_{2} \mathrm{O} ; P=0.046\right)$. Furthermore, a trend of higher in-hospital mortality was observed in the intubated patients ( 18.8 vs. $0 \% ; P=0.061)$. Multivariate logistic regression analysis showed that $1-2 \mathrm{~h}$ after NIV initiation, $\mathrm{a} \mathrm{PaO}_{2} / \mathrm{FiO}_{2}$ of $\leq 200 \mathrm{mmHg}$ (odds ratio [OR], 9.35; 95\% confidence interval [CI], 1.84-47.62; $P=0.007$ ) and NIV as the rescue therapy (OR, 5.43; 95\% CI, 1.09-27.12; $P=0.039$ ) were the risk factors for intubation (Table 1).

In the subgroup analysis of NIV as the rescue therapy, the medium time of using HFNO before NIV was 2 (IQR, 0.4-3.0) days, and the intubation rate at day 28 from hospital admission was much higher when comparing with NIV as the initial therapy (64.7 vs. $22.7 \% ; P=0.007$; Figure 2 ), as well as the intubation rate from symptom onset ( $P=0.005$; Table 2). Furthermore, hospitalization duration was longer when NIV was used as the rescue therapy (42.0 [IQR, 31.5-52.5] days vs. 34.5 [IQR, 26.642.4] days; $P=0.005)$. There was no difference in clinical characteristics before initiating noninvasive respiratory support

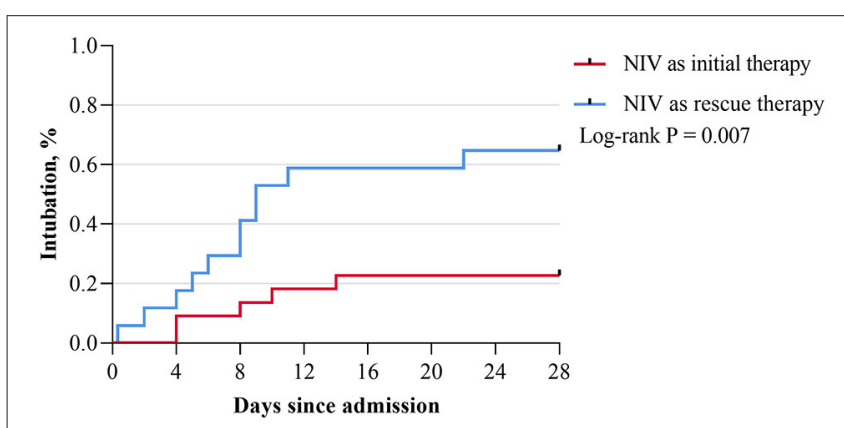

FIGURE 2 | Kaplan-Meier survival curve of the intubation rate at day 28 after admission. NIV, noninvasive ventilation.
(HFNO or NIV), the time interval from symptom onset to initiating noninvasive respiratory support (initial therapy: 10.0 [IQR, 8.3-13.0] days vs. rescue therapy: 10.0 [IQR, 5.0-11.0] days, $P=0.307$ ) and the in-hospital mortality (initial therapy: $4.5 \%$ vs. rescue therapy: $11.8 \%, P=0.570$ ) between patients who received NIV as initial therapy and those who received NIV as rescue therapy; however, $\mathrm{PaO}_{2} / \mathrm{FiO}_{2}$ was observed to be lower before initiating NIV in the latter (144.2 [IQR, 119.6-175.5] mmHg vs. 174.4 [IQR, 158.0-208.7] mmHg; $P=0.034$ ) (Table 2).

\section{DISCUSSION}

Our findings indicate that in patients with COVID-19-related AHRF receiving NIV, a $\mathrm{PaO}_{2} / \mathrm{FiO}_{2}$ of $\leq 200 \mathrm{mmHg}$ after $1-2 \mathrm{~h}$ of NIV initiation and using NIV as the rescue therapy are associated with a higher risk of intubation.

Recently, Franco et al. (13) performed a multicentered, retrospective study to analyze the feasibility and efficacy of using noninvasive respiratory support in patients with COVID-19related AHRF outside ICU. All patients only used one form of noninvasive respiratory support (NIV/CPAP or HFNO) during the hospitalization. The results found that the 30-day mortality, intubation rate and length of hospitalization were similar among different noninvasive respiratory support methods, but HFNO was usually used for patients with mild COVID-19 in their clinical practice. Similar to Franco's study, we also tended to use HFNO in mild patients, but patients in our study would receive NIV as the rescue therapy when HFNO failed to improve the clinical status of patients. Actually, some medical staff in China and some consensus tended to choose HFNO as the first choice, especially during the early pandemic, because it is easy to use and has good tolerance (14). In cases where severe respiratory distress or hypoxemia could not be relieved via HFNO, NIV was used as the rescue therapy. Subsequently, the treatment failure may be related to the delayed use of NIV when using it as the rescue therapy, leading to a low $\mathrm{PaO}_{2} / \mathrm{FiO}_{2}$ before NIV initiation (Table 2). The rate of NIV treatment failure in our study population was comparable to those reported in two previous observational studies ( 41.0 vs. 44.6 vs. $49.3 \%)(13,15)$. However, on excluding the patients using NIV as the rescue therapy in our study, the failure rate would be much lower (rescue therapy: $64.7 \%$ vs. initial therapy: $22.7 \%$ ). It might imply that when using HFNO as the initial treatment for mild COVID19 patients, patients should be closely monitored in order to avoid the delayed escalation of respiratory support. In addition, our team proposed that when considering treatment rationale, adjustable pressure, oxygen consumption, and tolerance, NIV should be considered as the first-line therapy to treat patients with mild acute respiratory distress syndrome (ARDS) (6).

Furthermore, in line with Frat's findings that $1 \mathrm{~h}$ after NIV initiation, a $\mathrm{PaO}_{2} / \mathrm{FiO}_{2}$ of $\leq 200 \mathrm{mmHg}$ and a tidal volume of $>9 \mathrm{~mL} / \mathrm{kg}$ of predicted body weight are the independent predictors of intubation among patients with AHRF, we found that after initiating NIV therapy, a $\mathrm{PaO}_{2} / \mathrm{FiO}_{2}$ of $\leq 200 \mathrm{mmHg}$ is an essential predictor of intubation in patients (16). We could not record the expired tidal volume because of the 
TABLE 2 | Comparison of baseline clinical characteristics and outcomes in patients who used NIV as initial or rescue therapy.

\begin{tabular}{|c|c|c|c|}
\hline & $\begin{array}{l}\text { NIV as initial therapy } \\
\qquad(n=22)\end{array}$ & $\begin{array}{l}\text { NIV as rescue therapy } \\
\qquad(n=17)\end{array}$ & $p$-value \\
\hline Age, years & $62.5(59.3-69.0)$ & $62.0(59.0-66.0)$ & 0.944 \\
\hline Male, $n(\%)$ & $12(54.5)$ & $14(82.4)$ & 0.093 \\
\hline $\mathrm{BMl}, \mathrm{kg} / \mathrm{m}^{2}$ & $24.8(22.0-27.4)$ & $24.8(22.9-26.6)$ & 0.726 \\
\hline The time interval from symptom onset to initiating noninvasive respiratory support, days & $10.0(8.3-13.0)$ & $10.0(5.0-11.0)$ & 0.307 \\
\hline The time interval from initiating HFNO to using NIV therapy, days & - & $2(0.4-3.0)$ & N.A. \\
\hline \multicolumn{4}{|l|}{ Comorbidities } \\
\hline Chronic respiratory disease, $n(\%)$ & $0(0)$ & $3(17.6)$ & 0.074 \\
\hline Hypertension, $n(\%)$ & 7 (31.8) & $7(41.2)$ & 0.738 \\
\hline Chronic cardiovascular disease, $n(\%)$ & $4(18.2)$ & $4(23.5)$ & 0.709 \\
\hline Chronic kidney disease, $n$ (\%) & $0(0)$ & $1(5.9)$ & 0.436 \\
\hline Chronic hepatic disease, $n(\%)$ & $1(4.5)$ & $1(5.9)$ & 0.851 \\
\hline Diabetes, $n(\%)$ & $4(18.2)$ & $3(17.6)$ & 0.966 \\
\hline Cancer, $n(\%)$ & $1(4.5)$ & $1(5.9)$ & 0.851 \\
\hline \multicolumn{4}{|l|}{ Clinical data before noninvasive respiratory support* } \\
\hline Respiratory rate, breaths/min & $24.5(23.0-27.5)$ & $22.0(20.0-25.0)$ & 0.076 \\
\hline Heart rate, breaths/min & $85.0(75.3-88.8)$ & $82.0(80.0-89.0)$ & 0.893 \\
\hline $\mathrm{pH}$ & $7.46(7.43-7.48)$ & $7.46(7.45-7.47)$ & 0.928 \\
\hline $\mathrm{PaO}_{2}, \mathrm{mmHg}$ & $72.3(61.1-79.2)$ & $73.0(61.5-73.8)$ & 0.872 \\
\hline $\mathrm{PaO}_{2} / \mathrm{FiO}_{2}, \mathrm{mmHg}$ & $174.4(158.0-208.7)$ & $179.27(165.9-224.1)$ & 0.468 \\
\hline \multicolumn{4}{|l|}{ Clinical data before NIV therapy } \\
\hline Respiratory rate, breaths/min & $24.5(23.0-27.5)$ & $25.0(23.0-29.0)$ & 0.410 \\
\hline Heart rate, breaths/min & $85.0(75.3-88.8)$ & $78.0(74.0-87.0)$ & 0.319 \\
\hline $\mathrm{pH}$ & $7.46(7.43-7.48)$ & $7.45(7.43-7.47)$ & 0.317 \\
\hline $\mathrm{PaO}_{2}, \mathrm{mmHg}$ & $72.3(61.1-79.2)$ & $72.0(65.3-81.0)$ & 0.664 \\
\hline $\mathrm{PaO}_{2} / \mathrm{FiO}_{2}, \mathrm{mmHg}$ & $174.4(158.0-208.7)$ & $144.2(119.6-175.5)$ & 0.034 \\
\hline \multicolumn{4}{|l|}{ Clinical outcomes } \\
\hline \multirow[t]{2}{*}{ Intubation, $n$ (\%) } & $5(22.7)$ & $11(64.7)$ & $0.007^{+}$ \\
\hline & & & $0.005^{\#}$ \\
\hline Hospitalization duration, days & $35.0(29.0-41.0)$ & $42.0(33.0-52.0)$ & 0.005 \\
\hline In-hospital mortality, $n$ (\%) & $1(4.5)$ & $2(11.8)$ & 0.570 \\
\hline
\end{tabular}

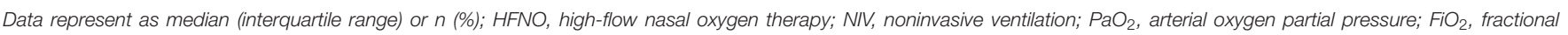
inspired oxygen; N.A., Not applicable.

*Noninvasive respiratory support refers to the HFNO or NIV; ${ }^{+}$intubation rate from hospital admission; ${ }^{*}$ intubation rate from symptom onset.

emergency situation during the pandemic and the retrospective nature of the study. However, studies have pointed that the pathophysiological characteristics of some patients with COVID19 who are diagnosed with ARDS according to the Berlin definition are not entirely consistent with those of patients with typical ARDS, presenting with the mismatch of severe hypoxia and relatively good respiratory compliance (17). Therefore, whether the targeted tidal volume of patients with COVID19-related early ARDS receiving NIV may be higher, especially among those with hypercapnia, would need more evidence in further studies (18).

Whether NIV treatment would increase the risk of viral transmission among medical staff has always been a matter of concern and debate over the past few years (19). Previous studies have shown that the maximum distance of exhaled air dissemination will be increased when using noninvasive respiratory support (20). However, there is no direct evidence indicating an increased risk of infection among medical workers while using NIV, and none of the medical staff was infected during NIV procedures performed under adequate protection in our study $(20,21)$. In future studies, further exploration will be needed regarding (1) the relationship between the use of NIV and the amount of virus dissemination and (2) the relationship between viral pathogenicity and the dilution effect of the increased ventilation volume.

The prone position could improve oxygenation by recruiting the collapsed region of the dorsal lung and promoting drainage of airway secretions in AHRF patients $(22,23)$. Recently, researchers applied prone position NIV in patients with COVID-19-related AHRF and found that it could reduce respiratory rate, improve oxygenation and comfort of patients (24). More evidence on 
the benefits of the prone position NIV should be investigated by comparing with standard NIV and selecting the appropriate patients are needed in the future.

Obviously, our study has some limitations. First, some clinical variables or ventilator parameters could not be analyzed due to the retrospective study design. Moreover, this was a single center study with a small sample size, which could not get adequate power to draw definitive conclusions. However, this study included all patients with COVID-19-related AHRF receiving NIV in the city of Shenzhen (with 423 laboratoryconfirmed cases on August 31, 2020), and these results could provide some help for the medical staff to select appropriate patients receiving NIV treatment. In future, largescale prospective randomized control studies are warranted to give us more evidence for the use of NIV and further studies should also explore the treatment effect of different NIV modalities or interface in patients with COVID-19related AHRF.

In conclusion, close attention should be paid to $\mathrm{PaO}_{2} / \mathrm{FiO}_{2}$ after 1-2 h of NIV initiation in patients with COVID-19-related AHRF receiving NIV. In addition, using NIV as rescue therapy should draw our awareness that it might delay escalation of respiratory support and lead to adverse outcomes.

\section{REFERENCES}

1. Wang D, Hu B, Hu C, Zhu F, Liu X, Zhang J, et al. Clinical characteristics of 138 hospitalized patients with 2019 novel coronavirus-infected pneumonia in Wuhan, China. Jama. (2020) 323:1061-9. doi: 10.1001/jama.2020.1585

2. Tobin MJ, Laghi F, Jubran A. Caution about early intubation and mechanical ventilation in COVID-19. Ann Intensive Care. (2020) 10:78. doi: 10.1186/s13613-020-00692-6

3. Crummy F, Naughton MT. Non-invasive positive pressure ventilation for acute respiratory failure: justified or just hot air? Intern Med J. (2007) 37:1128. doi: 10.1111/j.1445-5994.2007.01268.x

4. Nicolini A, Stieglitz S, Bou-Khalil P, Esquinas A. Cost-utility of noninvasive mechanical ventilation: analysis and implications in acute respiratory failure. A brief narrative review. Respir Investig. (2018) 56:207-13. doi: 10.1016/j.resinv.2017.12.011

5. Jahagirdar D, Picheca L. Heated Humidified High Flow Oxygen for Respiratory Support: A Review of Clinical Effectiveness, Cost-Effectiveness, and Guidelines. CADTH Rapid Response Reports, Ottawa, ON (2019).

6. Guan L, Zhou L, Le Grange JM, Zheng Z, Chen R. Non-invasive ventilation in the treatment of early hypoxemic respiratory failure caused by COVID-19: considering nasal CPAP as the first choice. Crit Care. (2020) 24:333. doi: 10.1186/s13054-020-03054-7

7. Ferreyro BL, Angriman F, Munshi L, Del Sorbo L, Ferguson ND, Rochwerg B, et al. Association of noninvasive oxygenation strategies with all-cause mortality in adults with acute hypoxemic respiratory failure: a systematic review and meta-analysis. JAMA. (2020) 324:5767. doi: 10.1001/jama.2020.9524

8. Ni YN, Luo J, Yu H, Liu D, Ni Z, Cheng J, et al. Can high-flow nasal cannula reduce the rate of endotracheal intubation in adult patients with acute respiratory failure compared with conventional oxygen therapy and noninvasive positive pressure ventilation?: a systematic review and metaanalysis. Chest. (2017) 151:764-75. doi: 10.1016/j.chest.2017.01.004

9. Raoof S, Nava S, Carpati C, Hill NS. High-flow, noninvasive ventilation and awake (nonintubation) proning in patients with coronavirus disease 2019 with respiratory failure. Chest. (2020) 158:1992-2002. doi: 10.1016/j.chest.2020.07.013

\section{DATA AVAILABILITY STATEMENT}

The raw data supporting the conclusions of this article will be made available by the authors, without undue reservation.

\section{ETHICS STATEMENT}

The studies involving human participants were reviewed and approved by the ethics committee of the Third People's Hospital. Written informed consent for participation was not required for this study in accordance with the national legislation and the institutional requirements.

\section{AUTHOR CONTRIBUTIONS}

LL, CQ, and RC contributed to determining the outline and content of the study. YF, LG, WW, and SZ contributed to retrieving literature and writing a draft of this manuscript. JY, JW, $\mathrm{ZL}$, and $\mathrm{SZ}$ contributed to the data acquisition, the interpretation of outcomes, and data analysis. All authors contributed to revising the draft critically for important intellectual content, providing final confirmation of the revised version, and being responsible for all aspects of the work.

10. Winck JC, Ambrosino N. COVID-19 pandemic and non invasive respiratory management: every Goliath needs a David. An evidence based evaluation of problems. Pulmonology. (2020) 26:213-20. doi: 10.1016/j.pulmoe.2020.04.013

11. Rochwerg B, Brochard L, Elliott MW, Hess D, Hill NS, Nava S, et al. Official ERS/ATS clinical practice guidelines: noninvasive ventilation for acute respiratory failure. Eur Respir J. (2017) 50:1602426. doi: 10.1183/13993003.02426-2016

12. National Health Commission of the People's Republic of China. Diagnosis and Treatment Guideline of COVID-2019, 8th edn. Available online at: http:// www.nhc.gov.cn/yzygj/s7653p/202008/0a7bdf12bd4b46e5bd28ca7f9a7f5e5a. shtml (accessed November 10, 2020).

13. Franco C, Facciolongo N, Tonelli R, Dongilli R, Vianello A, Pisani L, et al. Feasibility and clinical impact of out-of-ICU noninvasive respiratory support in patients with COVID-19-related pneumonia. Eur Respir J. (2020) 56:2002130. doi: 10.1183/13993003.02130-2020

14. Frat JP, Coudroy R, Thille AW. Non-invasive ventilation or high-flow oxygen therapy: when to choose one over the other? Respirology. (2019) 24:72431. doi: 10.1111/resp.13435

15. Aliberti S, Radovanovic D, Billi F, Sotgiu G, Costanzo M, Pilocane $\mathrm{T}$, et al. Helmet CPAP treatment in patients with COVID-19 pneumonia: a multicentre cohort study. Eur Respir J. (2020) 56:2001935. doi: 10.1183/13993003.01935-2020

16. Frat JP, Ragot S, Coudroy R, Constantin JM, Girault C, Prat G, et al. Predictors of intubation in patients with acute hypoxemic respiratory failure treated with a noninvasive oxygenation strategy. Crit Care Med. (2018) 46:20815. doi: 10.1097/CCM.0000000000002818

17. Chiumello D, Busana M, Coppola S, Romitti F, Formenti P, Bonifazi M, et al. Physiological and quantitative CT-scan characterization of COVID19 and typical ARDS: a matched cohort study. Intensive Care Med. (2020) 46:2187-96. doi: 10.1007/s00134-020-06281-2

18. Gattinoni L, Chiumello D, Caironi P, Busana M, Romitti F, Brazzi L, et al. COVID-19 pneumonia: different respiratory treatments for different phenotypes? Intensive Care Med. (2020) 46:1099-102. doi: 10.1007/s00134-020-06033-2

19. Guan L, Zhou L, Zhang J, Peng W, Chen R. More awareness is needed for severe acute respiratory syndrome coronavirus 2019 transmission through 
exhaled air during non-invasive respiratory support: experience from China. Eur Respir J. (2020) 55:2000352. doi: 10.1183/13993003.00352-2020

20. Ferioli M, Cisternino C, Leo V, Pisani L, Palange P, Nava S. Protecting healthcare workers from SARS-CoV-2 infection: practical indications. Eur Respir Rev. (2020) 29:200068. doi: 10.1183/16000617.0068-2020

21. Esquinas AM, Egbert Pravinkumar S, Scala R, Gay P, Soroksky A, Girault C, et al. Noninvasive mechanical ventilation in highrisk pulmonary infections: a clinical review. Eur Respir Rev. (2014) 23:427-38. doi: 10.1183/09059180.00009413

22. Guerin C, Reignier J, Richard JC, Beuret P, Gacouin A, Boulain T, et al. Prone positioning in severe acute respiratory distress syndrome. NEngl J Med. (2013) 368:2159-68. doi: 10.1056/NEJMoa1214103

23. Coppo A, Bellani G, Winterton D, Di Pierro M, Soria A, Faverio $\mathrm{P}$, et al. Feasibility and physiological effects of prone positioning in non-intubated patients with acute respiratory failure due to COVID-19 (PRON-COVID): a prospective cohort study. Lancet Respir Med. (2020) 8:765-74. doi: 10.1016/S2213-2600(20)30268-X
24. Sartini C, Tresoldi M, Scarpellini P, Tettamanti A, Carco F, Landoni $\mathrm{G}$, et al. Respiratory parameters in patients with COVID-19 after using noninvasive ventilation in the prone position outside the intensive care unit. JAMA. (2020) 323:2338-40. doi: 10.1001/jama. 2020.7861

Conflict of Interest: The authors declare that the research was conducted in the absence of any commercial or financial relationships that could be construed as a potential conflict of interest.

Copyright @ $2021 \mathrm{Fu}$, Guan, Wu, Yuan, Zha, Wen, Lin, Qiu, Chen and Liu. This is an open-access article distributed under the terms of the Creative Commons Attribution License (CC BY). The use, distribution or reproduction in other forums is permitted, provided the original author(s) and the copyright owner(s) are credited and that the original publication in this journal is cited, in accordance with accepted academic practice. No use, distribution or reproduction is permitted which does not comply with these terms. 